Studia Anglica Posnaniensia 48, 4, 2013

doi: 10.2478/stap-2013-0013

\title{
EARLY OLD ENGLISH NOMINAL SYSTEM: SYNCHRONIC DECLENSIONS IN THE VESPASIAN PSALTER
}

\author{
PAULINA KOLASIŃSKA
}

Faculty of English, Adam Mickiewicz University in Poznań

\begin{abstract}
The study analyzes the Early Old English nominal system from a synchronic perspective, since a diachronic approach is unable to provide an accurate description of the language. The analysis is based on the full text of the Vespasian Psalter interlinear gloss. The nouns were grouped according to their inflectional endings, thus representing the synchronically functioning nominal system of Early Old English, contrary to the traditional, diachronic classification, which uses reconstructed stems to classify nouns. The Vespasian Psalter model is compared and contrasted with the latest 'classical' work on Old English, Hogg and Fulk's A Grammar of Old English. Volume 2: Morphology (2011), which also aims at presenting Old English from a synchronic perspective.
\end{abstract}

Keywords: morphology, Early Old English, inflection, inflectional endings, nouns, grammatical gender, paradigm

\section{Introduction}

Most Old English textbooks, from the oldest, such as Wright \& Wright (1914), Campbell (1959), to the most recent, such as Hogg \& Denison (2006), offer a diachronic presentation of the Old English nominal system, that is, a presentation based on stems reconstructed from earlier stages of the language's history. The diachronic approach is the organizing principle of the majority of studies in historical linguistics, as the very idea of this field implies a chronological perspective. Thus, diachrony is an indispensible tool for discussing language history and development (Hansen 2001: 13). The model for the Old English nominal system based on reconstructed stems is economical, concise, and thus attractive from the pedagogical perspective (Carstairs 1987). However, traditional 
accounts of the Old English nominal system, primarily intended to elegantly present the system based on historical developments, are by definition unsuitable for capturing the language at a given, specific moment in its history. The diachronic models is unable to show which paradigms were in use in Old English and what their frequency was; neither is it able to show paradigm productivity. These problems are the reason why the classification has been criticized (Levin 1969; Hogg 1997; Krygier 1998, 2002; Hogg \& Fulk 2011). In answer to this criticism, a synchronic approach is proposed in this article. The aim of the synchronic approach is to reflect the state of the language at a particular moment in its history. Its advantage over diachronic studies is that it does not operate with reconstructed forms but with the existing inflectional markers; it analyzes the language in its actual shape. Lately such a reclassification of the Early Old English nominal system has been presented in Hogg \& Fulk (2011). However, as this study will also try to show, their classification seems oversimplified and, in fact, not purely synchronic. The aim of this study is to synchronically analyze the nouns which appear in the Vespasian Psalter and to construct a model for these nouns, which would be based on the visible inflectional markers - the inflectional ending.

\subsection{Data}

The Vespasian Psalter (MS. Cotton Vespasian A.I; Kuhn 1965), which represents the Mercian dialect of Old English, has been used as the data source. It is believed to have been produced at St. Augustine's (Canterbury) around 720730, and the interlinear Old English gloss was added in the mid-ninth century. It was the first extended translation of the psalms into English (Lapidge 2001: 460). The interlinear gloss closely follows the Latin original, however, since the focus of the study is to analyse Early Old English inflectional markers, rather than syntactic relationships, the translation's faithfulness should not affect the results. All the nouns, after verification in the original gloss, have been checked against the glossary to the Vespasian Psalter (Grimm 1906). The list thus compiled contains every noun in every inflectional form, as many times as it appears in the original text. All the proper nouns found in the data have been excluded from the inflectional analysis so as not to distort the results, as they often inflect anomalously due to their foreign origin.

\section{Hogg \& Fulk’s (2011) synchronic model}

Hogg and Fulk (2011) observe that due to the changes which Old English had undergone, reconstructed stems are a poor basis for the classification of synchronically existing nouns. Therefore, they employ a synchronic approach, 
based predominantly on inflectional endings, thus recognizing $a s$-declension, $a$ declension, an-declension, and minor declensions (2011: 69-145). The first three declensions are discussed together with their allophonic and gender variants, and minor declensions are divided into minor $a$-plurals, mutation plurals, and miscellanea, a loose collection of "nouns which seem to form discrete but small paradigms of their own" (Hogg \& Fulk 2011: 136). Hogg and Fulk do not provide any statistical data, commenting on the paradigms productivity in such vague ways as 'the largest and most important of all the OE declensions' (Hogg \& Fulk 2011:72). The inflectional sets presented in Hogg and Fulk together with their most important allomorphic variants are summarized in Table 1: (see Appendix, p. 44).

Such a presentation of Old English nominal declensions seems to be extremely economical at first, especially in comparison with such monumental and elaborate works as the classical Campbell's Old English Grammar (1959). However, considering the number of allophonic variants, the nominal system as presented in Hogg and Fulk is practically identical with the one presented in Campbell (1959), as can be seen in Tables 2 and 3 (Appendix, p. 45).

Their reclassification, though described as synchronic, actually uses historical processes to account for the allophonic variations, which means that the synchronic character of their study is questionable.

\section{The Vespasian Psalter synchronic model}

The present analysis takes into account all the nouns from the Vespasian Psalter, as many times as they occur in the manuscript. In total, seven hundred and seventy-four nouns have been analyzed. The qualitative analysis of types, i.e. unique nouns, has suggested that synchronically three major groups and a collection of ungrouped patterns can be distinguished for Early Old English. Each group consists of a set of patterns which are assumed to be related on the basis of the similarity of their inflectional endings. It was impossible to group twelve patterns as belonging to a larger class. In case of over half of the nouns it was impossible to identify the inflectional pattern due to its incompleteness. Twenty-two proper names appeared in the data and these nouns have not been analyzed at all as most of them inflect anomalously. The results for tokens have been analyzed in order to verify the frequency of each inflectional pattern and assess how characteristic it was for Early Old English (see Table 4 in the Appendix, p. 46). 


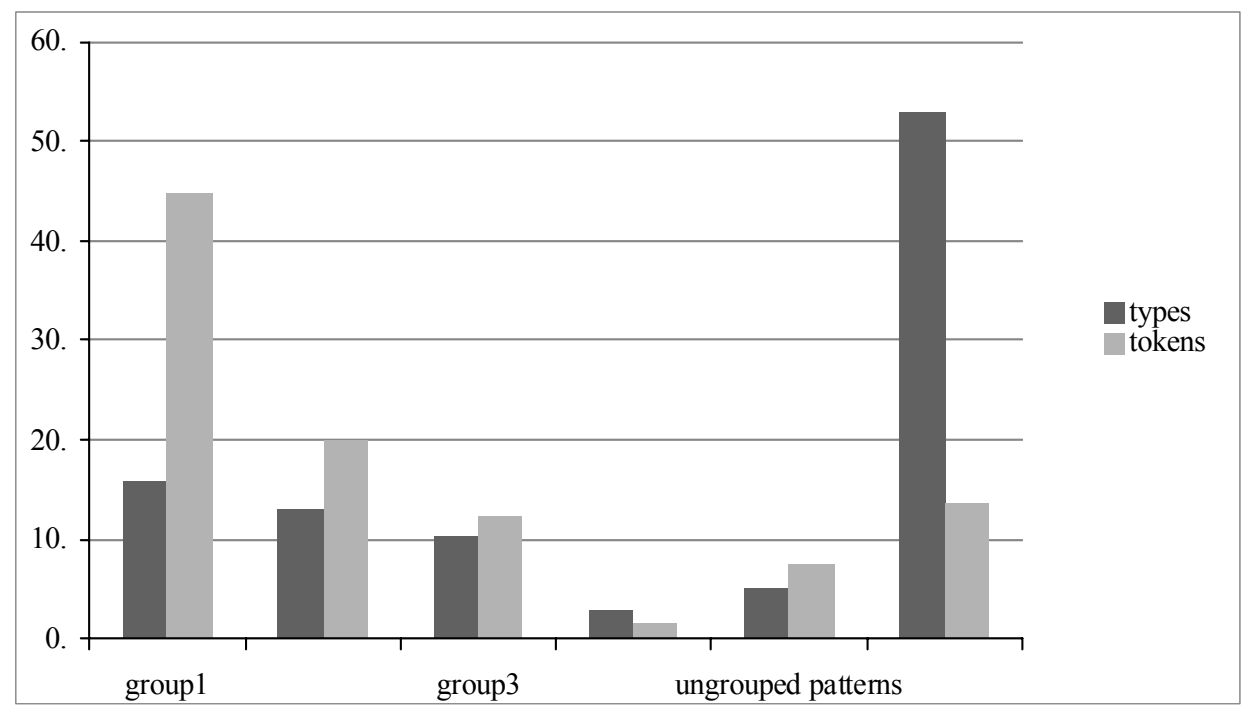

Figure 1. Types and tokens distribution in the Vespasian Psalter model: a comparison.

The major class consists of 3 inflectional groups. There are in total one hundred and twenty-three nouns in the Vespasian Psalter which belong to Group 1 (Table 5 in the Appendix), which accounts for $16 \%$ of types and $45 \%$ of tokens. Members of group 1 are $100 \%$ identical in the singular and only $50 \%$ identical in the plural, however, the pattern for the plural is the same for all the patterns which belong to that group (nominative/vocative is the same as accusative). The inflectional patterns which belong to this group - in the singular - always have the zero inflectional ending in the nominative and the accusative, -es for the genitive, and $-e$ in the dative. As to the plural, as has been said, the nominative is always identical with the accusative, with three possible inflectional endings: $-a s,-u$, and zero, and the genitive plural ending in $-a$. The types/tokens ratio suggests that Group 1 accounts for the most frequently appearing nouns in the manuscript, and it may possibly be the most characteristic group for Early Old English. Some examples of nouns classified as belonging to group 1 are cyning, doeg, engel, folk, feond and god.

Group 2 (see Table 6 in the Appendix), the second most prominent group, which accounts for $13 \%$ of types and $20 \%$ of tokens (one hundred nouns in the Vespasian Psalter), is dominated by the $-e$ exponent. Patterns from group 2 are $80 \%$ identical with one another, except for nominative and accusative singular, and the dative plural, all the other case-numbers are expressed by $-e$ (and the case-number exponent for dative plural is $-u m$ ). The nominative and the accusative singular can be marked with the zero inflectional ending, $-e$ or 
$-u$, which reflects the grammatical gender of Old English nouns. There are two problems with classifying a noun as belonging to a particular pattern from Group 2, as unless a noun appears in the contrastive case-number combinations, it is impossible to tell the patterns apart. Another problem with the classification is that $-e$ is not a case-number exponent characteristic only of Group 2, hence the number of unclassifiable nouns. The types/token ratio indicates that these nouns, though numerous, do not appear as frequently as those representing Group 1. Some examples classified as belonging to Group 2 are blis, halignis, moeht, song, syn and trymenis.

Group 3 (Table 7 in the Appendix), which accounts for 10\% of types and $12 \%$ of tokens (eighty-nine nouns in the Vespasian Psalter), is characterized by the conspicuous - an ending. Similarly to Group 2, Group 3 is $80 \%$ identical, and individual patterns within the group are similarly difficult to distinguish, as it is impossible to identify the pattern unless a noun appears in a contrastive casenumber. The low types/tokens ratio may mean that these nouns were neither numerous nor frequent, so probably they were of lower productivity, and they were definitely the least characteristic of Early Old English from the major groups. Some examples of nouns classified as belonging to group 3 are draca, ege, heorte, noma and woelle.

The ungrouped patterns (including incomplete patterns, see Table 8 in the Appendix) are a collection of patterns which could not be classified with any of the groups due to the fact that they are more than $20 \%$ different from all the identified patterns and from one another. There are 12 such patterns and they account for about $5 \%$ of types and $7 \%$ of tokens. These nouns may simply be lexicalized items rather than synchronically working paradigms, which is also supported by the fact that they account for very few nouns (from one to seven); that many of these patterns appear in their incomplete paradigms; and that there are so few examples of them in the data - thirty-nine in total. All these arguments considered, it would indeed seem that ungrouped patterns are fossilized items of marginal importance to the inflectional model of Early Old English.

The analysis has shown that inflectional patterns are not of equal prominence; indeed, there are actually only three groups of inflectional patterns which are of major importance, and together they account for about $85 \%$ of all the nouns with identifiable patterns. The remaining $15 \%$ include proper names and ungrouped/fossilized patterns. The study indicates that the grammatical gender of Old English nouns is often reflected in morphology (when compared with the diachronic model) and thus it functions synchronically; it may account for the differences between members of the same inflectional groups. The analysis has also shown that the nominal system is far from clear. This is due to not only variation within one inflectional group but also the fact there is a limited number of possible case-number exponents, and therefore pattern identification is 
often impossible; in fact, for more than $50 \%$ of types it was impossible to identify the inflectional pattern. There are two main reasons for this ambiguity. Firstly, most of the nouns in the Vespasian Psalter (four hundred and fiftyseven, i.e., 59,2\%) appear in only one or two forms, which is usually not enough to identify a noun's pattern. To compare, when a noun appears in 3 of its forms, it is possible to identify the inflectional pattern in $65 \%$ of all the cases, while when a noun appears in only one case-number form, it is possible to identify the pattern in only $15 \%$ of all the cases. The patterns of two hundred and fifty-one nouns which appear in one form cannot be identified, which means that $78,44 \%$ of nouns which appear in one form have unidentifiable inflectional patterns. Secondly, there is a limited choice of case-number exponents and, apart from group 3, which is conspicuous due to the -an ending, the remaining case-number exponents are shared by different patterns and groups, though in different combinations. Thus, it is the combination of case-number exponents that makes a pattern unique, distinctive and conspicuous. It has been noticed that the minimum number of case-number forms in which a noun should appear to identify its inflectional pattern is four, preferably including the combination of nominative and accusative plural, and dative singular.

4. The Vespasian Psalter synchronic model and Hogg \& Fulk's (2011) synchronic model

Hogg \& Fulk's (2011) synchronic model lists relatively few nominal declensions, thus it is seemingly economical. However, the allomorphic variants of these declensions are explained diachronically; thus, this model is not purely synchronic. The Vespasian Psalter model, in turn, offers a purely synchronic study based on one text, and the nouns are classified only according to the inflectional endings which actually appear in the data. The division into major and minor declensions is based on Hogg and Fulk's criterion of open:closed and large:small, which means that major declensions are open, i.e. they can accept new lexical items versus closed minor declensions; major declensions are also supposed to be large sets as opposed to small sets of minor declensions. This latter distinction is unclear in the case of Hogg \& Fulk (2011), who, as has been already said, do not provide any factual evidence for the size of each declension. Therefore it is difficult to verify the majority/minority of their groupings, while the Vespasian Psalter model is based on and supported by hard quantitative evidence which supports the majority or minority of a given inflectional pattern or group. Even more importantly, the nominal system - as presented in Hogg \& Fulk (2011) - seems to be clear and simple, while it has been shown here that as early as in Early Old English period, the system was highly far from clear and ordered, with relatively few case-number exponents, ambiguous to 
such an extent that it was impossible to identify the inflectional pattern in case of over $50 \%$ of the nouns which appeared in the data.

\section{Conclusions}

The aim of this study was to build a fully synchronic model of the nominal system of Old English, based on the data from the Vespasian Psalter. The analysis has shown that there seemed to be fewer functioning inflectional patterns in Old English than it is traditionally assumed; in fact, only three major inflections have been found, together with several minor, probably lexicalized inflectional patterns. The analysis also suggests that synchronically, the Old English nominal system is highly ambiguous: firstly, it is usually impossible to identify the exact noun-pattern; secondly, in over $50 \%$ of the types, it was impossible to identify both the pattern and group at all.

The Vespasian Psalter synchronic model has also been compared and contrasted with Hogg \& Fulk's (2011) version of the synchronic model. The comparison has shown a difference in classification, a different approach to quantitative analysis, and a suggestion that Hogg \& Fulk's (2011) model is actually a mixture of the two approaches, especially considering the fact that declensional variants are accounted for with diachronic information.

The results of this study call for further research, as obviously, one cannot draw definite conclusions from one text; it is obvious that case-number exponents differ among dialects. The Vespasian Psalter can only represent one dialect at one particular time, so the model based on this text must not be treated as a universal model for Early Old English. Indeed, a thorough synchronic study of the Mercian dialect of Early Old English would require more texts, just as to investigate Old English synchronically, it is necessary to analyze manuscripts representative of more than one dialect. However, the synchronic research could serve a comparative function: by analyzing manuscripts from different periods of time one can trace the developments in case-number marking, which may have numerous possible implications in the study of morphology, phonology, and syntax.

\section{REFERENCES}

PRIMARY SOURCES

Kuhn, Sherman M. (ed.). 1965. The Vespasian Psalter. Ann Arbor: University of Michigan Press. 


\section{SECONDARY SOURCES}

Aronoff, Mark. [1994] 1996. Morphology by itself: Stems and inflectional classes. (2nd edn.). Massachusetts: Massachusetts Institute of Technology.

Ball, C. J. E. 1970. The language of the Vespasian Psalter gloss: Two caveats. The Review of English Studies, New Series 21, 84. 462-465.

Beard, Robert. 1995. Lexeme-morpheme base morphology: A general theory of inflection and word-formation. Cambridge: SUNY Press.

Bertacca, Antonio. 2009. Natural Morphology and the loss of nominal inflections in English. Pisa: Pisa University Press.

Blevins, James P. 2003. Stems and paradigms. Language 79(4). 737-767.

Blevins, James P. 2006. Word-based morphology. Journal of Linguistics 42. 531-573.

Campbell, Alistair. 1959. Old English grammar. Oxford: Clarendon Press.

Carstairs, Andrew. 1983. Paradigm economy. Journal of Linguistics 19(2). 115-128.

Grimm, Conrad. 1906. Glossar zu dem Vespasian Psalter und den Hymnen. Heidelberg: Carl Winter's Universitätsbuchhandlung.

Hansen, Erik W. 2001. The synchronic fallacy. Historical investigations with a theory of history. Odense: Odense University Press.

Hogg, Richard M. 1997. Some remarks on case marking in Old English. Transactions of the Philological Society 95. 95-109.

Hogg, Richard M. 2005 [1992]. The Cambridge history of the English language. Vol. 1: The beginnings to 1066. Cambridge: Cambridge University Press.

Hogg, Richard M. \& R.D. Fulk. 2011. A grammar of Old English. Volume 2: Morphology. London: Wiley-Blackwell.

Koch, C. Friedrich. 1863. Laut- und Flexionslehre der englischen Sprache. Hermann Bohlau: Weimar.

Krygier, Marcin. 2002. A reclassification of Old English nouns. Studia Anglica Posnaniensia 38. 311-319.

Lapidge, Michael (ed.). [1999] 2001. The Blackwell encyclopedia of Anglo-Saxon England. Massachusetts: Blackwell Publishers Ltd.

Levin, Samuel R. 1969. A reclassification of the Old English strong verbs. In Roger Lass (ed.), 1969. Approaches to English historical linguistics. 249-257. New York: Holt, Rinehart and Winston.

Mertens-Fonck, Paule. 1985. The place of the Vespasian Psalter in the history of English. Studia Anglica Posnaniensia 17. 17-28.

Peinovich, Michael P. 1979. Old English noun morphology. A diachronic study. North Holland Publishing Company: Amsterdam.

Reszkiewicz, Alfred. 1996 [1973]. A diachronic grammar of Old English. Warszawa: Wydawnictwo Naukowe PWN.

Stewart, Thomas W. Jr. 2008. A consumer's guide to contemporary morphological theories. Working Papers in Linguistics 58. 138-230.

Stump, Gregory T. 2011. Inflectional morphology: A theory of paradigm-structure. Cambridge: Cambridge University Press.

Zwicky, Arnold M. 1985. How to describe inflection. In M. Niepokuj, M. Van Clay, V. Nikiforidou \& D. Feder (eds.). Proceedings of the Eleventh Annual Meeting of the Berkeley Linguistic Society. 372-386, Berkeley: Berkeley Linguistics Society. 
APPENDIX 


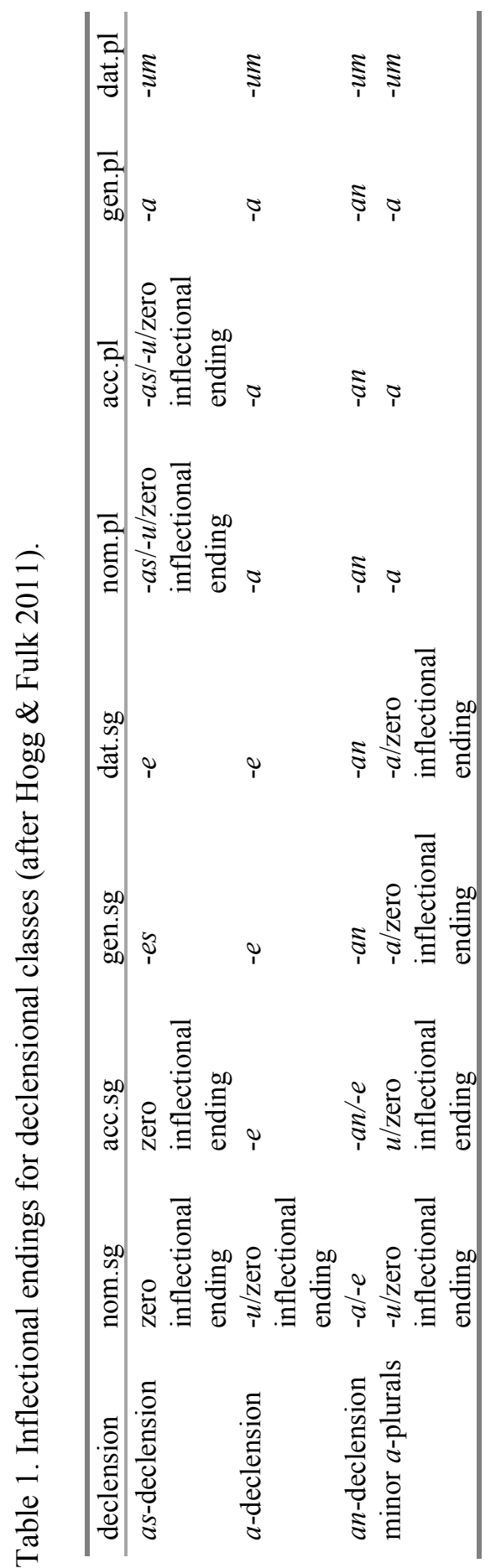


Early Old English nominal system ...

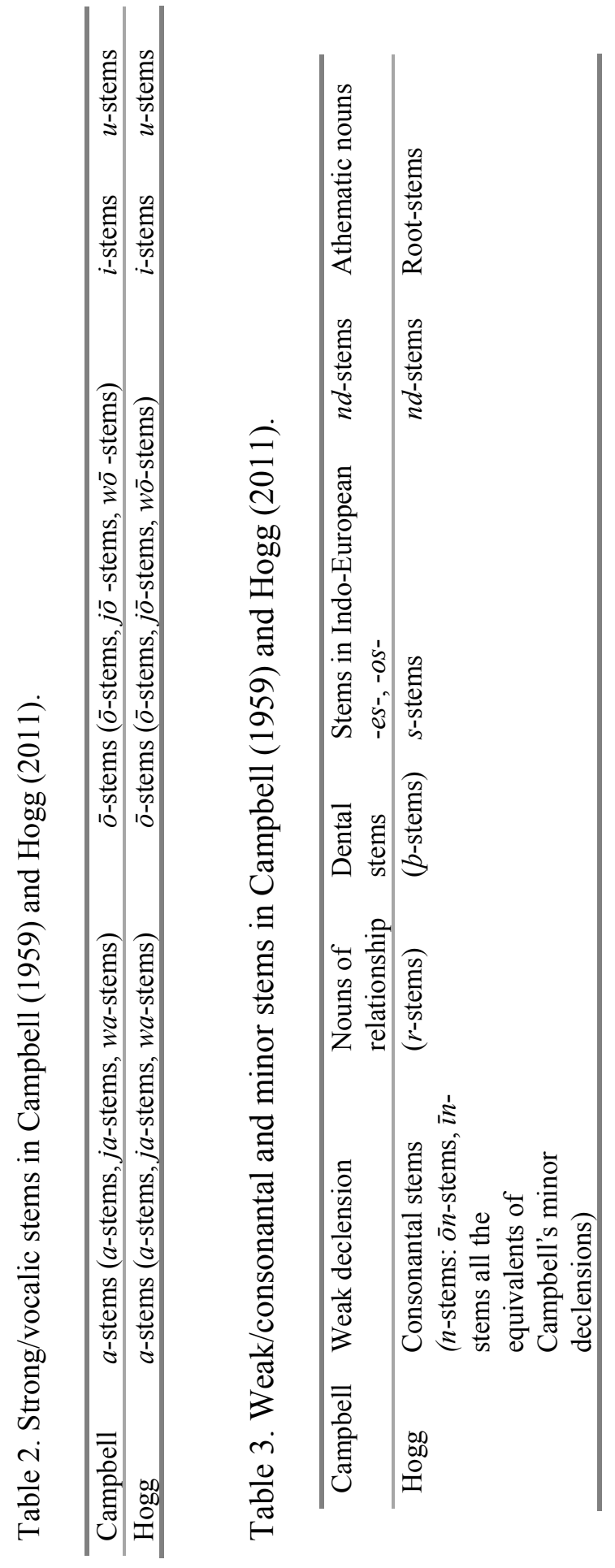




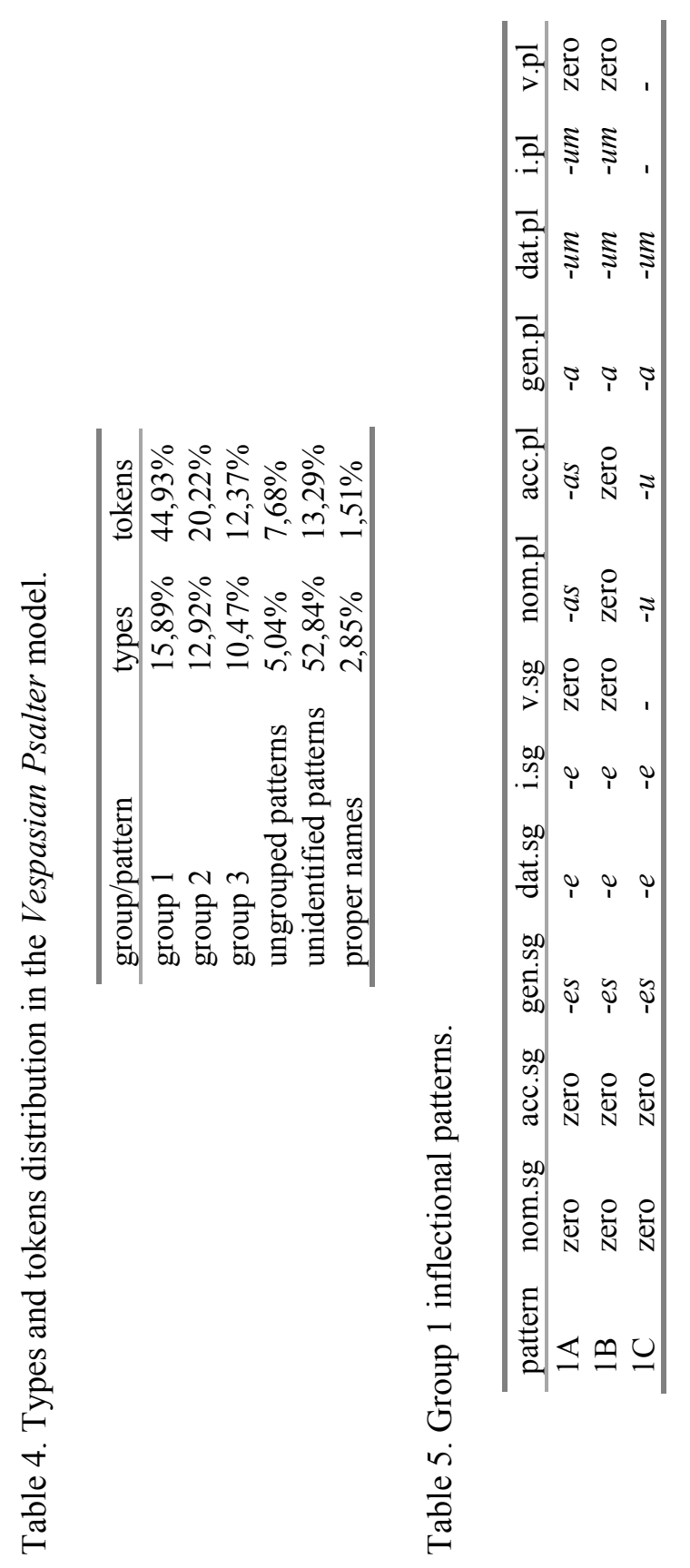




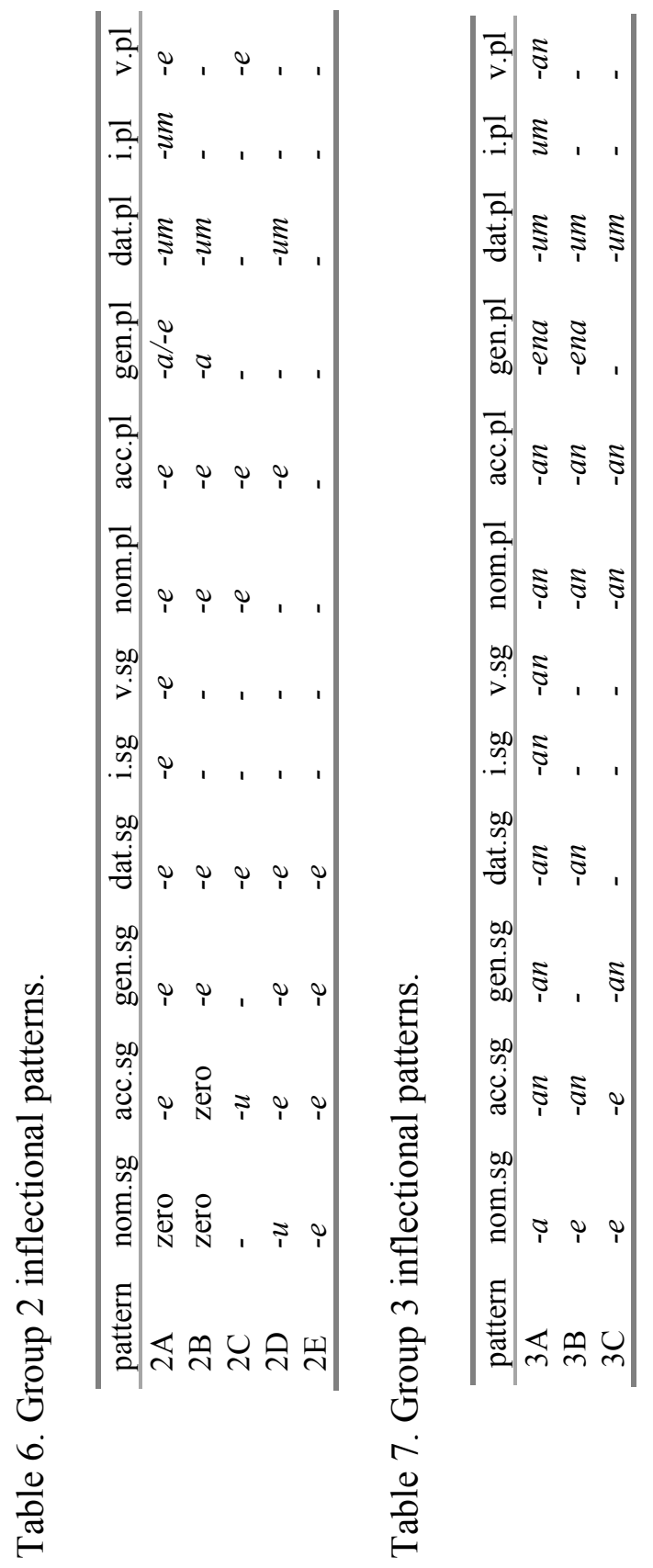




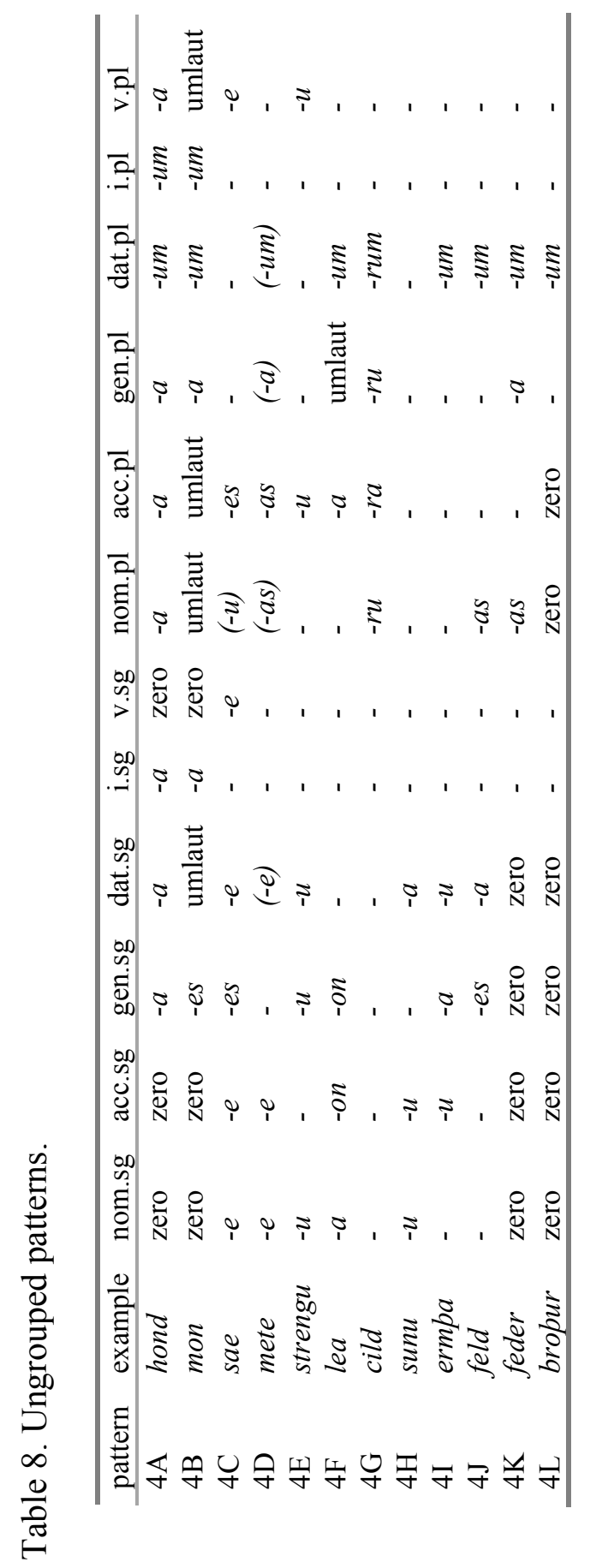

